\title{
Keaktifan Mengikuti Layanan Informasi Bidang Bimbingan Sosial Siswa Di Sekolah Menengah Atas Negeri 12 Pekanbaru
}

\author{
Nur Wisma ${ }^{1}$, Suci Habibah ${ }^{2}$ \\ ${ }^{1}$ Universitas Sriwijaya \\ ${ }^{2}$ Universitas Islam Negeri Sultan Syarif Kasim Riau \\ Article Info \\ Article history: \\ Received Jan $12^{\text {th }}, 2021$ \\ Revised Mar $20^{\text {th }}, 2021$ \\ Accepted Apr 26 ${ }^{\text {th }}, 2021$

\section{Keyword:} \\ SocialInformation Services, layanan \\ informasi, bimbingan siosial

\begin{abstract}
This research aims to see the activeness of exploring information services in the social sector of SMA Negeri 12 Pekanbaru students. This research is a quantitative descriptive research. The research population was all students of class XI, amounting to 347 people. . Sampling the authors drew 15\% of the population with the Proportional Random Sampling method. Data were collected using a questionnaire and documentation. To see the objective of exploring student social field data services, the percentage was descriptively analyzed. After the information obtained in the field was analyzed, it was concluded that student activity in exploring social data services in SMA Negara 12 Pekanbaru was categorized as active. These results were obtained from the percentage of answers to the questionnaire which was $78.91 \%$.
\end{abstract}

\section{Corresponding Author:}

Nur Wisma

Universitas Sriwijaya

Email: nurwisma@fkip.unsri.ac.id

\section{Pendahuluan}

Pendidikan adalah segala kondisi yang mempengaruhi pertumbuhan dan juga perkembangan individu. Adapun tujuan pendidikan yaitu mencerdaskan kehidupan bangsa dan meningkatkan kualitas sumber daya manusia dalam mewujudkan masyarakat yang maju adil dan makmur. Berdasarkan UU RI No 20 Tahun 2003 tentang Sistem Pendidikan Nasional, pada pasal 3 djelaskan bahwa:

"Pembelajaran pada pendidikan nasional berperan menumbuhkan kemampuan dan membentuk sifat serta perkembangan bangsa indonesia bermartabat budi luhur dalam rangka meningkatkan kecerdasan bangsa, bertujuan agar siswa memiliki kemampuan berkembang agar menjadi manusia yang beriman serta bertakwa kepada Tuhan, berakhlak, berilmu, dan menjadi masyarakat yang bertanggung jawab".

Hingga dari itu tempat pengembangan pembangunan pembelajaran itu merupakan pembelajaran formal ataupun non formal. Kenaikan mutu sumber energi manusia tidak bisa dipisahkan dari upaya kenaikan mutu pembelajaran yang saat ini lagi jadi sorotan serta 
harapan banyak orang di indonesia. Aktivitas pendidikan ialah proses transformasi pesan edukatif berbentuk modul belajar dari sumber belajar kepada pembelajar.

Bimbingan konseling ialah upaya dorongan yang diberikan oleh guru pembimbing kepada siswa yang memakai prosedur, metode serta bahan supaya siswa sanggup mandiri melalui layanan- layanan bimbingan dan konseling. Menurut Kamaluddin (2011) Pelayanan bimbingan dan konseling di sekolah merupakan usaha membantu peserta didik dalam pengembangan kehidupan pribadi, kehidupan sosial, kegiatan belajar, serta perencanaan dan pengembangan karir. Sedangkan Deni (2011) mengatakan bahwa untuk mengembangkan potensi siswa dan membantu memecahkan masalah yang dihadapi oleh para siswa perlu adanya kegiatan bimbingan dan konseling yang terorganisir, terprogram, dan terarah. berdasarkan hal tersebut berarti proses pembelajaran serta pendidikan di sekolah tidak hendak mendapatkan hasil yang maksimal tanpa sokongan layanan bimbingan konseling.

Pelayanan bimbingan secara handal di Indonesia hingga dikala ini difokuskan pada generasi muda yang masih duduk di bangku sekolah serta cuma terealisasi pada tahap pembelajaran sekolah hingga pada bangku perkuliahan (Winkel serta Hastuti, 2004). Pelayanan bimbingan di sekolah, salah satunya dilaksanankan dengan metode layanan informasi bidang sosial. Menurut Bahri, dkk (2017) Salah satu bidang bimbingan yang membantu peserta didk dalam mengenal lingkungan dan mengembangkan diri dalam hubungan sosial yang dilandasi budi pekerti luhur serta tanggung jawab kemasyarakatan dan kenegaraan yaitu bidang bimbingan sosial.

Salah satu faktor keberhasilan dalam layanan tersebut yang penting adalah keaktifan siswa, selain faktor kemampuan konselor sekolah dalam merencanakan dan melaksanakan layanan informasi bidang sosial.Keaktifan mengikuti layanan informasi bidang sosial tidak dapat muncul dengan sendirinya. Konselor/guru bimbingan dan konseling sekolah harus menciptakan situasi yang memungkinkan terciptanya layanan informasi yang menyenangkan, menarik, dan tidak monoton sehingga rasa ingin tahu siswa, dan motivasi siswa meningkat. Selain faktor keaktifan siswa, keberhasilan pelaksanaan layanan informasi bidang sosial, adalah tersedianya sarana - sarana penunjang, materi layanan mempengaruhi keberhasilan layanan informasi tersebut (Putri, 2009).

Jika ditinjau dari bidang bimbingan dan konseling, Bidang bimbingan sosial, membantu siswa mengenal dan berhubungan dengan lingkungan sosial yang dilandasi budi pekerti luhur, tanggung jawab kemasyarakatan dan kenegaraan (W.S Winkel, 2004). Serta pula cocok dengan tujuan dari bidang tutorial sosial ialah, supaya orang yang dibimbing sanggup melaksanakan interaksi sosial secara baik dengan lingkungannya. Bidang bimbingan sosial bisa dilaksanakan memakai layanan data atau informasi (Winkel dalam Tohirin, 2012) layanan informasi merupakan sesuatu layanan yang berupaya penuhi kekurangan orang hendak data yang mereka perlukan. Layanan informasi pula bermakna usaha- usaha buat membekali siswa dengan pengetahuan dan uraian tentang area hidupnya serta tentang proses pertumbuhan anak muda.

Lebih lanjut (Tohirin, 2012) mengatakan data yang diberikan dalam layanan data bidang individu serta sosial merupakan data tentang tahap-tahap pertumbuhan yang mencakup pertumbuhan raga, motorik, bicara, emosi, sosial, penyesuaian sosial, bermain, kreativitas, penafsiran, moral, seks, serta pertumbuhan karakter. Serta statment dari para pakar di atas, bisa disimpulkan kalau layanan informasi bidang sosial sangat menolong siswa dalam perkembangannya paling utama dalam lingkungannya dimanapun dia berada.

Sekolah Menengah Atas Negeri 12 Pekanbaru yang terdapat pada Kota Pekanbaru terletak pada Jalan Garuda Sakti KM.3. Sekolah Menengah Atas Negeri 12 melaksanakan layanan Bimbingan dan Konseling, serta pola BK yg dilaksanakan merupakan BK pola 17 plus. Di sekolah ini pun sudah memutuskan bimbingan dan konseling sebagai satu hal 
pendorong dan membantu anak didik pada perkembangan, secara optimal baik kepribadian, sosial kognitif, intelektual dan emosional. Pengajar pembimbing yang bertugas melaksanakan layanan BK berjumlah lima orang pengajar pembimbing. Di sekolah ini menggunakan program yang dibuat, pengajar pembimbing berusaha melaksanakan layanan bimbingan dan konseling. Salah satu layanan yang dilaksanakan di sekolah ini yaitu layanan informasi bidang sosial. Meskipun layanan informasi bidang sosial sudah terealisasi tetapi masih terdapat karakter anak didik yang aktif \& adapula yang kurang aktif. Perilaku aktif contohnya seperti: anak didik mau mendengarkan, anak didik berdiskusi baik pada kelompok kecil atau juga besar, anak didik menyampaikan pendapatnya, anak didik mengisi lembar tugas, anak didik bertanya. Sedangkan karakter kurang aktif contohnya seperti: anak didik berbicara sendiri, anak didik enggan berdiskusi \& hanya jalan-jalan di kelas, enggan mengerjakan lembar tugas, meninggalkan kelas dalam waktu bimbingan klasikal berlangsung.

Berdasarkan tanda-tanda yang peneliti temukan, peneliti tertarik untuk melakukan penelitian menggunakan judul "Keaktifan mengikuti Layanan Informasi Bidang Bimbingan Sosial Siswa pada Sekolah Menengah Atas Negeri 12 Pekanbaru".

\section{Metode}

Tujuan penelitian ialah agar mampu mengetahuikeaktifan siswa mengikuti layanan informasi bidang sosial terhadap komunikasi interpersonal siswa SMA Negeri 12 Pekanbaru. Sebagai subjek pada riset ini merupakan siswa-siswa kelas XI di SMA Negeri 12 Pekanbaru Tahun Pelajaran 2019/2020. Pada pengambilan sampel ini dilakukan dengan memakai teknik Proportional Random Sampling, ialah memakai perwakilan berimbang. Pengambilan sampel secara acak yang seimbang ini peneliti mengambil sampel $15 \%$ dari masing-masing kelas sehingga mampu menghasilkan sampel sebesar 52 orang. Teknik pengumpulan data penelitian menggunaan instrument sekala Likert terdiri dari 17 item untuk angket layanan informasi bidang sosial siswa dengan menuliskan alternatif jawaban sangat setuju, setuju, kurang setuju, tidak setuju, dan sangat tidak setuju. Analisis data yang digunakan dalam penelitian ini memakai pendekatan kuantitatif. Agar mampu menjawab rumusan masalah, data yang didapatkan dianalisis secara statistik yakni menggunakan rumus persentase.

\section{Hasil dan Pembahasan}

Berdasarkan hasil data didapat mendapatkan jawaban angket tentang keaktifan mengikuti layanan informasi bidang bimbingan sosial yang telah di diisi responden yang berjumlah 52 orang sebagaimana perhitungan pada tabel dibawah ini:

Tabel Rekapitulasi Jawaban Angket

Keaktifan Mengkiuti Layanan Informasi Bidang Sosial

\begin{tabular}{|c|c|c|c|c|c|c|c|c|c|c|c|c|c|}
\hline \multirow{3}{*}{$\begin{array}{c}\text { No } \\
\text { Item }\end{array}$} & \multirow{3}{*}{ Tabel } & \multicolumn{10}{|c|}{ Alternatif Jawaban } & \multirow{2}{*}{\multicolumn{2}{|c|}{ Jumlah }} \\
\hline & & \multicolumn{2}{|c|}{$\mathbf{S}$} & \multicolumn{2}{|c|}{ SR } & \multicolumn{2}{|c|}{ KK } & \multicolumn{2}{|c|}{ JR } & \multicolumn{2}{|c|}{ TP } & & \\
\hline & & $\mathbf{F}$ & $\%$ & $\mathbf{F}$ & $\%$ & $\mathbf{F}$ & $\%$ & $\mathbf{F}$ & $\%$ & $\mathbf{F}$ & $\%$ & $\mathbf{F}$ & $\%$ \\
\hline 1 & IV.3 & 26 & 50 & 14 & 27 & 11 & 21 & 1 & 2 & - & - & 52 & 100 \\
\hline 2 & IV.4 & 23 & 44 & 25 & 48 & 4 & 8 & - & - & - & - & 52 & 100 \\
\hline 3 & IV.5 & 43 & 83 & 8 & 15 & 1 & 2 & - & - & - & - & 52 & 100 \\
\hline 4 & IV.6 & 34 & 65 & 16 & 31 & 2 & 4 & - & - & - & - & 52 & 100 \\
\hline
\end{tabular}




\begin{tabular}{|c|c|c|c|c|c|c|c|c|c|c|c|c|c|}
\hline 5 & IV.7 & 26 & 50 & 17 & 33 & 9 & 17 & - & - & - & - & 52 & 100 \\
\hline 6 & IV.8 & 19 & 36 & 28 & 54 & 5 & 10 & - & - & - & - & 52 & 100 \\
\hline 7 & IV.9 & 17 & 33 & 26 & 50 & 9 & 17 & - & - & - & - & 52 & 100 \\
\hline 8 & IV.10 & - & - & 4 & 8 & 13 & 25 & 18 & 34 & 17 & 33 & 52 & 100 \\
\hline 9 & IV.11 & 1 & 2 & 2 & 4 & 15 & 29 & 19 & 36 & 15 & 29 & 52 & 100 \\
\hline 10 & IV.12 & - & - & 5 & 10 & 16 & 31 & 18 & 34 & 13 & 25 & 52 & 100 \\
\hline 11 & IV.13 & 21 & 40 & 27 & 52 & 4 & 8 & - & - & - & - & 52 & 100 \\
\hline 12 & IV.14 & 29 & 56 & 20 & 38 & 3 & 6 & - & - & - & - & 52 & 100 \\
\hline 13 & IV.15 & 16 & 31 & 16 & 31 & 17 & 32 & 3 & 6 & - & - & 52 & 100 \\
\hline 14 & IV.16 & 21 & 40 & 21 & 40 & 9 & 17 & 1 & 2 & - & - & 52 & 100 \\
\hline 15 & IV.17 & 25 & 48 & 16 & 31 & 10 & 19 & 1 & 2 & - & - & 52 & 100 \\
\hline 16 & IV.18 & 28 & 54 & 16 & 31 & 6 & 11 & 2 & 4 & - & - & 52 & 100 \\
\hline 17 & IV.19 & 25 & 48 & 20 & 38 & 7 & 13 & - & - & - & - & 52 & 100 \\
\hline JUMLAH & 354 & 680 & 281 & 541 & 141 & 270 & 63 & 120 & 45 & 87 & 884 & \\
\hline
\end{tabular}

\section{Hasil}

analisisKeaktifanSiswaMengikutiLayananInformasiBidangSosialmelaluiRumusPersentase

$$
\begin{array}{r}
\mathrm{P}=\frac{F}{N} \times 100 \% \\
=\frac{3488}{4420} \times 100 \% \\
=78.91 \%
\end{array}
$$

Berdasarkan skor $78.91 \%$ melewati rentang $61-80 \%$, sehingga dapat diambil kesimpulan jika keaktifan siswa SMA Negeri 12 Pekanbaru dalam menjajaki layanan.

Penelitian ini bertujuan agar mampu melihat keaktifan mengikuti layanan informasi bidang sosial siswa SMA Negeri 12 Pekanbaru. Sebagai subjek dalam penelitian ini adalah siswa-siswa kelas XI di SMA Negeri 12 Pekanbaru Tahun Pelajaran 2019/2020. Pengambilan sampel dilakukan melalui teknik Proportional Random Sampling, yang meliputi penggunaan perwakilan berimbang. Pengambilan sampel acak dengan seimbang ini peneliti menarik sampel $15 \%$ dari setiap kelas dan menghasilkan sampel sekitar 52 orang. Dari hasil perhitungan peneliti menggunakan rumus persentase mendapatan hasils kor $78.91 \%$ berada pada rentang 61-80\% sehingga diambil kesimpulan bahwa keaktifansiswa SMA Negeri 12 Pekanbaru tergolong aktif. Keaktifan merupakan kegiatan yang dilaksanakan siswa untuk berusaha mendapatkan ilmu. Keaktifan siswa pada riset ini merupakan semua kegiatan siswa dan kemauan mengikuti layanan informasi bidang sosial, misalnya siswa mampu mendengarkan dengan baik, mencatatnya, aktif bertanya dan berani mengutaraan pendapatnya. Keaktifan yang disebutkan yaitu pada siswa, karena melalui keaktifan siswa dalam proses pemberian layanan akan tercipta perubahan tingkah laku atau karaktersiswa dengan baik dan berkembang.

Dari output analisis data tersebut, dapatlah dilihat betapa pentingnya layanan informasi, khususnya dalam bidang bimbingan sosial,yang diperlukan bisa membimbing individu agar bisa melakukan interaksi sosial secara baik pada lingkunganya, yakni bertingkahlaku yang baik \& bisa diterima lingkungan sosialnya. Tentunya wajib sinkron menggunakan kebiasaan-kebiasaan \& nilai-nilai yang berlaku pada masyarakat. Menurut Djumhur\& Surya (Tohirin, 2007) bimbingan sosial adalah bimbingan yang bertujuan agar mampu membantu individu dalam memecahkan \& mengatasi kesulitan-kesulitan perkara sosial. (Prayitno, 2004) ada tiga alasan utama mengapa pemberian informasi perlu diselenggarakan. Pertama, membekali individu menggunakan berbagai pengetahuan mengenai lingkungan yang diharapkan mampu memecahkan kasus yang dihadapi 
berkenaan menggunakan lingkungan sekitar, pendidikan, jabatan, maupun sosial budaya. Kedua, memungkinkan individu agar bisa memilih arah hidupnya. Ketiga, setiap individu merupakan sesuatu yang unik. Keunikan itu akan membawakan pola-pola bertindak yang bhineka diselesaikan menggunakan aspek-aspek kepribadian masing-masing. Sehingga melalui bimbingan sosial bisa membantu anak didik pada bersosial dilingkungannya dengan baik dan mengatasi permasalahan tersebut, lantaran bimbingan sosial merupakan bimbingan yg diarahkan kepada individu/sekelompok orang agar bisa membantu \& mengatasi permasalahan siswa yg terkait pada aspek kehidupan eksklusif individu baik pada segi mental seorang \& pada kehidupan sosial baik pada segi pergaulan, sikap toleransi, dan kerjasama yg bertujuan buat melengkapi individu hingga mempunyai wahana yang relatif bagi individu pada melaksanakan fungsi sosialnya (Yahya \&Winarsih, 2016).

Layanan informasi bidang bimbingan sosial adalah suatu layanan yg sangat krusial pada memberikan fakta-fakta yg bermanfaat pada perkembangan sosialnya, khususnya pada membina eksklusif yg bisa berinteraksi sosial menggunakan lingkunganya. Sesuai menggunakan pendapat (Tohirin, 2012) bahwa tujuan primer bimbingan sosial merupakan agar individu yg dibimbing bisa melakukan hubungan sosial secara baik dengan lingkunganya. Menurut (Nasution, 2004) sekolah terbatas kemampuanya buat membarui situasi sosial, tetapi sekolah bisa mengugah nilai-nilai \& sikap anak secara individual, rasa keadilan, rasa keagaman, yang mengemukakan dihadapan dewa kemudian melihat nilainilai itu pada hubunganya menggunakan orang-orang yang dianggapnya rendah, asing, licik, \& sebagainya. Cara ini bisa dilakukan melalui anugerah fakta, diskusi kelompok, hubungan pribadi, dan sebagainya. Dengan seringnya anak didik menerima layanan informasi bidang bimbingan sosial maka akan bisa menambah keterangan pada anak didik mengenai cara-cara membina hubungan atau interaksi sosial yang serasi menggunakan lingkungan sosialnya, sehinga keterangan tadi bisa digunakanya menjadi acuan pada bersikap dan bertingkah laris pada kehidupanya sehari-hari. Jadi jelaslah bahwa layanan keterangan bidang bimbingan sosial memiliki dampak yang relatif mampu membina anak didik sebagai manusia yang bisa melakukan hubungan sosial secara baik pada lingkup lingkunganya. Hal ini juga diungkapkan Nuraini, dkk (2021) bahwa layanan bidang bimbingan sosial sangat efektif untuk meningkatkan kemampuan beradaptasi siswa, baik dengan guru maupun teman di sekolah dan lingkungannya, karena dalam bimbingan sosial dilatih untuk menyesuaikan diri atau beradaptasi dengan baik, sehingga sangat membantu dalam upaya meningkatkan kemampuan beradaptasi siswa.

Berdasarkan output penelitian lain dari (Putri, 2009) menerima output bahwa taraf keaktifan mengikuti bimbingan klasikal dalam anak didik kelas IX Sekolah Menengah pertama Pangudi Luhur I Timoho, Yogyakarta tahun ajaran 2008/2009 sangat tinggi \& tinggi. Artinya, bahwa keaktifan anak didik itu ditentukan pada baik tidaknya progam bimbingan, kepribadian pengajar bimbingan \& konseling atau konselor sekolah, hubungan yang baik antara konselor sekolah pada anak didik, serta anak didik mampu berkembang secara optimal.

Kelebihan dari penelitian ini ialah mampu menghasilkan data tentang keaktifan mengikuti layanan informasi bidang sosial pada siswa SMAN 12 Pekanbaru, riset ini mampu mendapatkan pengetahuan baru bagi peneliti mengenai variabel yang dipakai. Namun peneliti masih menyadari jika riset ini masih ada beberapa keterbatasan, yakni pada saat mengambil responden penelitian, serta pada riset ini dilakukan disatu tempat saja yakni di SMA N 12 Pekanbaru. Riset dilakuan dengan sebaik-baiknya, namun keterbatasan yang dihadapi yaitu kurang proporsionalnya penyebaran data pada aspek-aspek demografisnya. Jadi riset ini masih memerlukan penelitian lebih terperinci dan lanjut dalam menentukan jumlah subjek atau persebaran datanya dalam setiap aspek demografisnya. Sehingga 
diharapkan riset berikutnya mampu menghasilkan penelitian yang lebih komprehensif.

\section{Kesimpulan}

Dari data yang berhasil dikumpulkan dan penyajian data serta penghitungan data pada penelitian yang dilakukan tentang Keaktifan Mengikuti Layanan Informasi Bidang Bimbingan Sosial Siswa Sekolah Menengah Atas Negeri 12 Pekanbaru, diambil kesimpulan bahwasannya keaktifan siswa mengikuti layanan informasi bidang bimbingan sosial SMA Negeri 12 pekanbaru tergolong aktif yaitu sekitar 78.91\%. Agar keaktifan ini lebih meningkat disarankan guru bimbingan dan konseling lebih meningkatkan kualitas dan kreatifitas dalam pemberian layanan khususnya layanan informasi. Kreatifitas dari guru pembimbing dalam menyampaikan layanan bimbingan konseling khususnya layanan informasi merupakan salah satu faktor penentu kesuksesan pelaksanaan bimbingan konseling disekolah. Dengan bervariasinya metode yang diberikan, maka siswa juga akan tertarik untuk mengikuti setiap kegiatan bimbingan konseling..

\section{References}

Abdullah, M. (2002).Membangun Komunikasi yang Efektif. Yogyakarta: Mentari Pustaka.

Bahri, S., Alam, A. A., \& Supiati, S. (2017). Pengaruh Layanan Informasi Bidang Bimbingan Sosial Terhadap Perkembangan Perilaku Sosial Siswa. Jurnal Konseling Andi Matappa, 1(1), 30-38.

Depdikbud. (2002). Kamus Besar Bahasa Indonesia, Jakarta: Balai Pustaka.

Deni, F. (2011). Bimbingan konseling. Yogyakarta: Teras.

http://kartiniumar.blogspot.com/2013/01/bidang-bimbingan-sosial 9450

Indonesia UU No. 20 Tahun 2003 Tentang Sistem Pendidikan Nasional, Jakarta: Asa Mandiri

Kamaluddin, H. (2011). Bimbingan dan konseling sekolah. Jurnal Pendidikan dan Kebudayaan, 17(4), 447-454.

Nanang, M. (2011). Metode Penelitian Kuantitatif (Analisis Isi dan Analisis Data Sekunder), Jakarta: Raja GrafindoPersada.

Nuraini, N., Nuraeni, N., \& Sulastri, N. M. (2021). Pengaruh Bimbingan Sosial Terhadap Kemampuan Beradaptasi Siswa Kelas VIII SMPN 2 Batukliang Kabupaten Lombok Tengah. Realita: Jurnal Bimbingan dan Konseling, 5(2).

Prayitno.(2004). Layanan Informasi. Padang: UNP Press.

Prayitno.,\& Erman, A. (2006). Dasar-dasar Bimbingan Konseling, Jakarta: Reineka Cipta.

Putri, B.A.P. (2009). Tingkat Keaktifan Mengikuti Bimbingan Klasikal Pada Siswa Kelas IX SMP Pangudi Luhur I Yogyakarta Tahun Ajaran 2008/2009. Skripsi. Yogyakarta: Universitas Sanata Dharma.

Redja, M. (2002). Pengantar Pendidikan, Jakarta: Raja Grafindo Persada.

Riduwan. (2010). Skala Pengukuran Variabel-variabel Penelitian, Bandung: Alfabeta.

S.Nasution. (2004). Sosiologi Pendidikan. Jakarta: Bumi Aksara.

Sugiyono. (2012). Metode Penelitian Pendidikan (Pendekatan Kuantitatif, Kualitatif, dan R\&D), Bandung: Alfabeta.

Suharsimi, A. (2006). Prosedur Penelitian Suatu Pendekatan Praktek, Jakarta: Rineka Cipta.

Tohirin. (2012). Bimbingan dan Konseling di Sekolah dan Madrasah., Jakarta: Raja Grafindo Persada. 
Winkel dan Hastuti. (2004). Bimbingan dan Konseling di Institusi Pendidikan. Yogyakarta: Media Abadi

Yahya, A. D., \& Winarsih.(2016). Komunikasi Interpersonal Peserta Didik Kelas XI SMA Negeri 2 Padang Cermin Kabupaten Pesawaran. Jurnal Bimbingan dan Konseling, 03 (1), 41-56. 